\title{
An endangered snake thrives in a highly urbanized environment
}

\author{
Natalie M. M. Reeder ${ }^{1}$, Ryan M. Byrnes ${ }^{1}$, Ricka E. Stoelting ${ }^{1,2}$, Karen E. Swaim ${ }^{1, *}$ \\ ${ }^{1}$ Swaim Biological, Inc., 4335 First St. PMB \#312, Livermore, California 94551, USA \\ ${ }^{2}$ Department of Forest and Wildlife Ecology, 1630 Linden Dr., University of Wisconsin-Madison, Madison, Wisconsin 53706, USA
}

\begin{abstract}
The endangered San Francisco garter snake Thamnophis sirtalis tetrataenia occurs in only 2 counties on the densely populated San Francisco Peninsula, California, USA. Due to its limited geographic range and destruction of populations by the rapid pace of urban development in the 1950s and 1960s, T. s. tetrataenia was the only snake included in the inaugural US Endangered Species Act. Several large areas preserved as public parks, utility lands, or private trusts support remnant populations that are the focus of recovery and conservation efforts. To assist in assessment of status and trend for this subspecies, we fit Huggins' closed capture models in RMark to mark-recapture data collected in 2007 and 2013 to estimate population size of an isolated population on a small (72.8 ha) property surrounded by residential development and transportation infrastructure. Our best supported models indicate a population of 1763 individuals (95\% CI: 1302-2446) in 2007 and 1761 (95\% CI: 1211-2639) in 2013. In addition, total captures of an important prey species increased 2 orders of magnitude from 829 in 2007 to 17180 in 2013. These findings highlight the potential for well-managed but small habitat units ('the good'), to compliment vast natural areas ('the ideal') in recovery and conservation strategies for threatened and endangered species that can be supported by a small home range.
\end{abstract}

KEY WORDS: Abundance $\cdot$ Mark-recapture $\cdot$ San Francisco garter snake $\cdot$ Thamnophis sirtalis tetrataenia $\cdot$ Urban ecology

\section{INTRODUCTION}

Habitat loss is a major cause of the decline in global biodiversity (Vitousek 1994, Sala et al. 2000). The dramatic alteration of natural habitats for agriculture, urban development, and transportation and energy infrastructure has decreased the amount of habitat available to native plant and wildlife species. Development also reduces connectivity among remaining habitat patches and can degrade habitat quality through pollution and disturbance (Krauss et al. 2010, Mora \& Sale 2011). Decreased habitat connectivity compromises population viability by reducing immigration and emigration, thus lowering genetic diversity and reducing chances of recolonization from source populations (Debinski \& Holt 2000). Habitat loss is widely regarded as the leading cause

*Corresponding author: kswaim@swaimbio.com of endangering species with extinction (Wilcove et al. 1998, Sala et al. 2000).

The San Francisco garter snake Thamnophis sirtalis tetrataenia is a federally endangered subspecies endemic to the densely populated San Francisco Peninsula in San Mateo and northern Santa Cruz Counties in California, USA (Blainville 1835, ESA 1973). Dense and rapid development that included filling natural freshwater wetlands, geographic isolation of populations due to human alterations of the landscape, and hobbyist collecting pressure resulted in the inclusion of $T$. s. tetrataenia on the inaugural species list of the US Endangered Species Act (USFWS 1967, ESA 1973). However, a few populations of T. $s$. tetrataenia are known to persist in publicly and privately protected open spaces where suitable natural and/or man-made aquatic habitats exist and are asso-

(C) The authors 2015. Open Access under Creative Commons by Attribution Licence. Use, distribution and reproduction are unrestricted. Authors and original publication must be credited. 
ciated with adequate upland within the species' historic range (Barry 1978, McGinnis 1984). The San Francisco garter snake relies on aquatic habitat to support its amphibian prey species, the California red-legged frog Rana draytonii and Sierran tree frog Pseudacris sierra (Fitch 1965, Larsen et al. 1991, Stebbins \& McGinnis 2012). Upland habitat is necessary to support thermoregulatory behaviors such as basking and aestivation, and offers a means of escape from threats, including potential predators (Fox 1951, Barry 1994, Larsen 1994).

The recovery plan for this endangered subspecies, written nearly 30 yr ago and prior to any systematic, range-wide status surveys or studies of population size, calls for the maintenance of 10 populations with at least 200 adults in a 1:1 sex ratio (USFWS 1985). Three decades later, progress toward recovery goals is uncertain due to a lack of consistency in sampling and analysis methods used to determine population sizes and trends. Population studies that use standardized and robust methods at multiple sites are critical to developing sound recovery and management strategies for this subspecies. A 1978 assessment that relied on visual encounter surveys identified 12 breeding populations on the San Francisco Peninsula (Barry 1978) and a 1987 technical report that used trapping and visual surveys identified 26 populations on public and private lands throughout the range (McGinnis 1984). Neither study estimated the sizes of these populations nor were the findings published in peer-reviewed literature. Subsequent attempts in the 1980 s and 1990 s to estimate population sizes and/or densities did not always incorporate detection probability measurements and therefore contain inestimable error. Advancements in statistical modeling of mark-recapture data over the past 20 yr now allow much more rigorous and in-depth analyses of population biology, in particular through incorporation of detection probabilities (and variability within) into demographic models (Williams et al. 2002). Halstead et al. (2011) were the first to publish such an analysis of one T. s. tetrataenia population, estimating 443 ind. on a large (213 ha), protected, coastal site contiguous with an even larger area of undeveloped habitat. Here, we undertake a similar study, albeit at a very different location: a relatively small (72.8 ha), disturbed, and isolated parcel of land, surrounded by dense urban development.

Differing from Halstead et al.'s (2011) large parcel, our study site is unique because of its small size, isolation, origin as non-habitat (a former brackish marsh converted to freshwater marsh), and intensive disturbance history. Because of the site's location in an urbanized matrix, exposure to pollution and disturbance is likely to be higher than in more 'natural' areas; thus, one might expect that the site's degraded habitat quality would limit the number of T. s. tetrataenia it could support. However, the snake was first collected near this area in 1968 (specimen CPJM 129, Coyote Point Junior Museum; reported in Barry 1994, p. 68), and several subsequent unpublished attempts to assess population size reported abundance or total captures anywhere from 200 to 700 ind. during the 1970s, 1980s, and 1990s (Wharton 1989, Barry 1994, Larsen 1994). As previously mentioned, methods were inconsistent across studies, but reported decreases in population estimates over time translated to concern that the T. s. tetrataenia population was declining at this site (USFWS 2006). Because of this concern, a recovery action plan was initiated on the property in 2008, prescribing wetland creation and other habitat enhancement projects. Habitat enhancements were intended to increase prey abundance and consequently stabilize or increase $T$. s. tetrataenia population size on the site.

To assist in determination of current status and trend of this T. s. tetrataenia population, we conducted replicated mark-recapture surveys and used wellestablished modeling techniques to estimate the population size in 2007 and again in 2013. Conducting the study with standardized methods at multiple time points allows us to compare population estimates over time. In addition, we identified and counted $R$. draytonii and $P$. sierra in order to determine relative prey abundance in both years. Our results have implications for recovery strategies, evaluation criteria, and prognosis for T. s. tetrataenia as well as for the conservation and recovery of other endangered species within small, modified habitat patches.

\section{MATERIALS AND METHODS}

\section{Site description}

Due to the threat of illegal collection of Thamnophis sirtalis tetrataenia, we do not disclose the exact location or ownership of the study site. However, we provide the following context: the site encompasses 72.8 ha of filled, historic brackish marshland abutting the San Francisco Bay in San Mateo County, California, measuring $3.6 \mathrm{~km}$ long, with width ranging from 0.44 to less than $0.07 \mathrm{~km}$. Currently, the site is composed of approximately 32.3 ha of storm drain canals, seasonal rain-fed ponds and marshes, and 40.5 ha of upland habitat dominated by non-native plant spe- 
cies (Wharton 1989, Larsen 1994); actual surface area of available water varies with annual weather fluctuations. Tidal gates prevent intrusion of brackish water into the freshwater aquatic habitats. No point on the site is farther than $734 \mathrm{~m}$ from a permanent water source, and during the wet season the maximum distance from aquatic habitat generally shrinks to approximately $300 \mathrm{~m}$. The site is bordered by a major interstate highway to the east, train tracks and urban development to the west, dense housing to the north and south, and is at least $2.5 \mathrm{~km}$ from the nearest known T. s. tetrataenia population. Water flows onto the site from underground storm drains through which immigration or emigration, while possible, is extremely unlikely.

Disturbance and modification of the site have been extensive. Upland areas were most likely lightly grazed and used for agriculture before the turn of the 19th century. Major changes took place between the 1930s and 1960s when development of housing tracts hemmed the parcel, highway construction restricted flow of water from the bay, and channelization of riparian areas and installation of tidal gates restructured the site's hydrology (Wharton 1989, Barry 1994, Larsen 1994). By the early 1970s, much of the former salt or brackish slough area had been filled and/or graded (Wharton 1989) and the site began to resemble its current topography. Canal routes were completed in the mid-1970s, and since that time, disturbance has become more localized and periodic in nature. The most prominent of these activities include construction and upgrade of transport and public utilities infrastructure, and dredging and clearing of vegetation from canals. To offset disturbance to the listed species on the site, habitat enhancement activities were initiated in the 1990s with the creation of small, seasonal ponds in former uplands. Most recently, a 2008 recovery action plan was implemented that included pond construction, physical removal of overgrown and non-native vegetation, and increased site security to prevent unauthorized access by the public. Between 2008 and 2013, these activities created approximately $1183 \mathrm{~m}^{2}$ of new aquatic habitat and restored approximately $6785 \mathrm{~m}^{2}$ of existing seasonal and perennial open water habitat (representing $\sim 2 \%$ of total available aquatic habitat on the site).

\section{Data collection}

A total of 87 drift fence and funnel traplines were installed at the study site in 2007 using a stratified randomized design to represent 3 habitat classes: marsh, upland, and canal bank. Habitat classifications followed Wharton (1989) and Larsen (1994). Trapline allocation was based on the proportion of available habitat except in the 'upland' category, where trapping effort was reduced based on previous observations that $T$. s. tetrataenia activity was centered on wetland areas (Wharton 1989, Larsen 1994). The 2007 trapline locations were replicated in 2013 except where changes in water levels and vegetation growth required minor location adjustments.

Traplines consisted of a drift fence (flexible hardboard $35.6 \mathrm{~cm}$ high $\times 7.62 \mathrm{~m}$ long) with 2 funnel traps located at each end. Each drift fence was set at least $5 \mathrm{~cm}$ below ground level to deter animals from crawling under the hardboard. Each funnel trap was constructed from a rectangular wooden frame covered by panels of $3.2 \mathrm{~mm}$ wire mesh. An internal-facing wire mesh funnel, narrowing to roughly $3.8 \mathrm{~cm}$ at the terminus, was secured into one end of each trap. To keep captured animals from exiting, circular Mylar flaps were affixed to the inner terminus of each funnel. Each trap was fitted with a recessed 'dish' filled with an anti-desiccant (SoilMoist ${ }^{\mathrm{TM}}$ saturated with tap water) to prevent desiccation of captured amphibians. One or 2 pieces of plywood measuring approximately $41 \times 51 \mathrm{~cm}$ were placed on top of each trap to provide shade.

Traps were active from 29 March to 1 July 2007, and from 8 April to 14 July 2013. Trapping was timed to coincide with the period of peak T. s. tetrataenia activity at this site from March through June (Wharton 1989, Larsen 1994) and to avoid the mid- to latesummer emergence of neonates, which are more vulnerable to injury or mortality in traps. Traps were checked either once in the early evening (to minimize the potential for rodents to cause injury or mortality of reptiles) or twice per day (early morning and early evening) when rainfall, humidity, or fog increased amphibian capture rates.

Upon first capture, all T. s. tetrataenia were measured for snout-to-vent length (SVL) to the nearest $\mathrm{mm}$ and inspected for presence of hemipenes to determine sex. Individuals $>300 \mathrm{~mm}$ SVL were injected with a passive integrated transponder (PIT tag). Individuals $\leq 300 \mathrm{~mm}$ SVL were classified as 'subadult', and individuals $>300 \mathrm{~mm}$ SVL were classified as 'adult.' Adults were gently palpated for the presence of embryos when time allowed. All snakes were released at the point of capture immediately after processing.

Amphibians were readily captured in the funnel traps. The number and age class of subadult and adult 
Rana draytonii and Pseudacris sierra were recorded with each trap check. Amphibians were not individually marked. All amphibians were released at the point of capture immediately after processing.

Rainfall data for the years and months of active trapping were obtained from the National Oceanic and Atmospheric Administration repository (www. cnrfc.noaa.gov/rainfall_data.php). The weather station that recorded these data is within $2 \mathrm{~km}$ of the study site.

\section{Data analysis}

Population estimates were derived with RMark (Laake 2013), using adult T. s. tetrataenia only. Within the 2 years sampled, we selected overlapping time periods with similar effort. These periods consisted of 60 active trap days from 5 April to 13 June 2007, and from 8 April to 9 June 2013. The 60 active trap days were divided into 10 trapping 'occasions' of 6 active trap days each to eliminate the effect of multiple recaptures in close succession (which occasionally occurred because snakes were released at point of capture, i.e. at traplines) and to reduce the likelihood that births or deaths occurred during any particular sampling occasion (to approximate the demographic closure assumption of the model used to estimate population size). For each snake in each year, a 10 digit capture history was generated, with either ' 1 ' or ' 0 ' representing capture or no capture, respectively, within each of the $6 \mathrm{~d}$ trapping occasions (e.g. 001010 for a snake captured on the 3rd and the 5th occasion of that particular year).

We assumed that the study population met assumptions of closure due to the geographic isolation and the short sampling period relative to the lifespan of the species. The lifespan of $T$. s. tetrataenia in the wild is not well known, but a closely related subspecies is thought to have lived nearly $20 \mathrm{yr}$ in captivity (Harding 1997). Neonates were not included in the analysis, therefore births did not affect our population sample. Further, Halstead et al. (2011) reported high annual survival rates for this subspecies $(\geq 0.74$, with $95 \% \mathrm{CL}$ ranging from 0.49 to 0.95$)$, indicating that mortality during our shorter sampling occasions could be assumed minimal. Therefore, Huggins' closed capture models (Huggins 1989, 1991) were used to derive estimates of population abundance $(N)$ and capture $(p)$ and recapture probabilities $(c)$.

We fit 5 a priori models to each study year: a null model with constant capture probabilities $[p(\sim 1) c()]$, a model with an effect of sex on capture probability $[p(\sim \operatorname{sex}) c()]$, a model with time-dependent capture probabilities $[p(\sim$ time $) c()]$, a model with the effect of sex constant over temporally-varying capture probabilities $[p(\sim$ time+sex $) c()]$, and a full model with the effect of sex on capture probability varying over time $[p(\sim$ time $\times \operatorname{sex}) c()]$. We set $p=c$ to maximize estimability of parameters in a sparse dataset. We confirmed that this was a reasonable approach with post hoc modeling which favored the $p=c$ parameterization over $p \neq c$. We used the median c-hat function in Program MARK (White \& Burnham 1999) to test goodness-of-fit of the full model, and to determine the variance inflation factor $(\hat{c})$ to adjust for overdispersion (Burnham \& Anderson 2002, 2004). We used Akaike's information criterion corrected for small sample size (AICc) to provide a measure of the fit of each model to the data. In cases where adding a single parameter resulted in a model ranked lower than the model without that parameter (i.e. a pretending variable; Anderson 2008), we removed that model from the candidate set and calculated model weights based on the reduced model set.

\section{RESULTS}

\section{Demographics}

Between 29 March and 1 July 2007, we captured 457 Thamnophis sirtalis tetrataenia ind. a total of 548 times (204 males, 247 females, 6 sex undetermined) over 81.5 active trap days. Of these individuals, $97 \%$ were categorized as adults (i.e. SVL $\geq 300 \mathrm{~mm}$ ). The mean SVL was $433 \mathrm{~mm}$ (range $=307-586 \mathrm{~mm}, \mathrm{n}=198$ ) for adult males and $469 \mathrm{~mm}$ (range $=301-766 \mathrm{~mm}$, $\mathrm{n}=243$ ) for adult females, reflecting an overall tendency toward larger size in females. At least 27 of 243 adult females were gravid $(11 \%$; SVL: mean = $565 \mathrm{~mm}$, mode $=515 \mathrm{~mm}$, range $=467-766 \mathrm{~mm})$, but it should be noted that not all females were palpated. The first gravid female was caught on 30 March, the second day of trapping. The observed sex ratio from this sample was biased toward females (0.81 M:F). Only 11 snakes were categorized as subadults (i.e. SVL between 200 and $300 \mathrm{~mm}$ ); 9 of these were sexed, resulting in mean SVLs for subadult males of $274 \mathrm{~mm}$ (range $=257-289 \mathrm{~mm}, \mathrm{n}=5$ ) and for subadult females of $283 \mathrm{~mm}$ (range $=255-299 \mathrm{~mm}$, $\mathrm{n}=4$ ). Only 3 neonates were captured, all after 21 June; these ranged in size from 152-165 mm, the smallest of which was male.

Between 8 April and 14 July 2013, we captured 333 T. s. tetrataenia ind. 379 times (185 males, 143 
females, 5 sex undetermined) over 70 active trap days, providing a sample roughly $3 / 4$ the size of the 2007 sample. No snakes captured in 2007 were recaptured in 2013. Similar to the previous survey, $96 \%$ of individuals captured in 2013 were categorized as adults. The mean SVLs for adults were slightly lower than those calculated in 2007: 418 $\mathrm{mm}$ for adult males (range $=311-532 \mathrm{~mm}, \mathrm{n}=$ 178 ) and $455 \mathrm{~mm}$ for adult females (range $=300$ $637 \mathrm{~mm}, \mathrm{n}=133$ ). As in 2007, females tended to be larger than males. Although not every female was palpated for embryos, at least 43 of the 143 adult females captured were gravid $(30 \%$; SVL: mean $=502 \mathrm{~mm}$, mode $=420 \mathrm{~mm}$, range $=368-$ $63 \mathrm{~mm})$. The first gravid female was captured on 16 April, in the second week of trapping. In contrast with the 2007 sample, the observed sex ratio for adult T. s. tetrataenia in 2013 was biased toward males (1.33 M:F). Of the 5 subadults captured, 4 were measured; SVLs for subadult males were 195 and $198 \mathrm{~mm}$, and for subadult females 211 and $214 \mathrm{~mm}$. A total of 15 neonates were captured. This reflects a larger sample than that obtained in 2007. In 2013, all neonate captures took place after 3 July; these had a mean SVL of 193 $\mathrm{mm}$ (range $=169-198 \mathrm{~mm}$ ), the smallest of which was female.

\section{Population estimates}

Goodness-of-fit testing revealed that our global models for 2007 and 2013 fit the data well, with estimated $\hat{c}$ of 1.18 and 0.99 , respectively, indicating dispersion within acceptable bounds. Therefore, model selection was based on AICc.

For 2007, capture histories from 349 ind. $>300 \mathrm{~mm}$ SVL were used to estimate population size. Model $p(\sim \operatorname{time}+\operatorname{sex}) c()$ was found to be pretending and therefore was removed from the candidate set. Of the remaining models, the top model $p$ ( time) $c()$ had overwhelming support with $99.2 \%$ model weight (Table 1). This model indicated that capture probability was low and varied over time, ranging from 0.033 to 0.006 , peaking during the first $4 \mathrm{wk}$ of trapping. Abundance was estimated at 1763 ind. (95\% CI: 1302-2446), with females outnumbering males (0.77 M:F), which translates to a density of 24.2 ind. ha $^{-1}$ (Table 2).

For 2013, 287 ind. $>300 \mathrm{~mm}$ SVL were used to estimate population size. Model ranking mirrored that of 2007, with model $p(\sim$ time+sex $c()$ pretending, and relative weight of models overwhelmed
Table 1. 2007 candidate models for San Francisco garter snake (Thamnophis sirtalis tetrataenia) capture probability $(p)$ and recapture probability $(c)$, ranked according to Akaike's information criterion corrected for small sample size (AICc). () = variable set equal to $p_{i}(\sim 1)=$ constant variable; $(\sim$ time $)=$ variation with time; $(\sim \operatorname{sex})=$ variation with sex; ' $x$ ' $=$ interactive parameter effects; Npar $=$ number of parameters; $\mathrm{AICC}=$ model AICc score; $\triangle \mathrm{AICC}=$ difference in AICc score from top model; Weight $=$ Akaike weight

\begin{tabular}{|lccccc|}
\hline Model & Npar & AICc & $\Delta$ AICc & Weight & Likelihood \\
\hline$p(\sim$ time $) C()$ & 10 & 1908.31 & 0.00 & 0.99 & 1888.25 \\
$p(\sim$ time $\times$ sex $) C()$ & 20 & 1917.89 & 9.57 & 0.01 & 1877.65 \\
$p(\sim 1) C()$ & 1 & 1946.09 & 37.78 & 0.00 & 1944.09 \\
$p(\sim \operatorname{sex}) C()$ & 2 & 1947.74 & 39.43 & 0.00 & 1943.74 \\
\hline
\end{tabular}

Table 2. Top model, $p$ (time) $c($ ), 2007 population estimates for San Francisco garter snake (Thamnophis sirtalis tetrataenia) females, males, and total number of individuals, with standard error (SE) and $95 \%$ confidence intervals (CI)

\begin{tabular}{|lcccc|}
\hline \multirow{2}{*}{ Sex } & \multirow{2}{*}{$\begin{array}{c}\text { Population } \\
\text { estimates }\end{array}$} & SE & \multicolumn{2}{c|}{ 95\% CI } \\
\cline { 4 - 5 } & & & Lower & Upper \\
Female & 995 & 161 & 737 & 1376 \\
Male & 768 & 127 & 565 & 1070 \\
Total & 1763 & - & 1302 & 2446 \\
\hline
\end{tabular}

by support for $p$ ( time) $c() \quad(99.7 \%$ model weight; Table 3$)$. Thus, our data again supported time-variation in capture probability. In 2013, capture probabilities were again low, ranging from 0.038 to 0.014 , and peaking during the first and fourth weeks of trapping. As in 2007, females outnumbered males (0.76 M:F), and total abundance was estimated at 1761 individuals (95\% CI: 1211-2639; Table 4), almost identical to the 2007 results. Thus, the density of the estimated T. s. tetrataenia population in 2013 was equal to that of 2007 .

Table 3. 2013 candidate models for San Francisco garter snake (Thamnophis sirtalis tetrataenia) capture probability $(p)$ and recapture probability $(c)$, ranked according to Akaike's information criterion corrected for small sample size (AICc). Npar = number of parameters. See Table 1 for description of model parameters

\begin{tabular}{|lccccc|}
\hline Model & Npar & AICc & $\Delta$ AICc & Weight & Likelihood \\
\hline$p(\sim$ time $) C()$ & 10 & 1514.854 & 0.000 & 0.997 & 1494.777 \\
$p(\sim$ time $\times$ sex $) C()$ & 20 & 1526.505 & 11.651 & 0.003 & 1486.211 \\
$p(\sim 1) c()$ & 1 & 1555.304 & 40.450 & 0.000 & 1553.303 \\
$p(\sim \operatorname{sex}) c()$ & 2 & 1557.111 & 42.257 & 0.000 & 1553.107 \\
\hline
\end{tabular}


Table 4. Top model, $p$ (time) $C$ (), 2013 population estimates for San Francisco garter snake (Thamnophis sirtalis tetrataenia) females, males, and total number of individuals, with standard error (SE) and $95 \%$ confidence intervals (CI)

\begin{tabular}{|lcccc|}
\hline Sex & \multirow{2}{*}{$\begin{array}{c}\text { Population } \\
\text { estimates }\end{array}$} & SE & \multicolumn{2}{c|}{ 95\% CI } \\
& Fower & Upper \\
Female & 1000 & 156 & 690 & 1494 \\
Male & 761 & 156 & 521 & 1145 \\
Total & 1761 & - & 1211 & 2639 \\
\hline
\end{tabular}

\section{Amphibian prey captures}

Amphibians were not marked and therefore analysis of mark-recapture data could not be used to produce a formal population size estimate for Pseudacris sierra or for Rana draytonii. Total captures in 2007 were 829 P. sierra (in $81.5 \mathrm{~d}$ of trapping) in contrast with 17180 captures in 2013 (in $70 \mathrm{~d}$ of trapping). The highest number of $P$. sierra captures in a single day was 862 ind. on 7 May 2013. A total of 29 R. draytonii captures were recorded in 2007 and 32 in 2013.

\section{Rainfall}

Rainfall was $43.18 \mathrm{~cm}$ for the $2006 / 2007$ rain year (1 October to 30 September) and $33.32 \mathrm{~cm}$ for 2012/ 2013. While traps were active, the site received $4.8 \mathrm{~cm}$ of rain in 2007 and $1.3 \mathrm{~cm}$ in 2013.

\section{DISCUSSION}

Our results indicate that spring population sizes of Thamnophis sirtalis tetrataenia at our study site were quite similar and dense in 2007 and 2013, bounding a 6 yr interval. Most notably, T. s. tetrataenia were present at a higher density at this study site than previously reported for the subspecies; an average of 1762 ind. were estimated equating to 24.2 ind. ha ${ }^{-1}$ across both years. Previous studies found T. s. tetrataenia to occur at 2.1 ind. ha ${ }^{-1}$ at a coastal site (Halstead et al. 2011), and 7.6 ind. ha ${ }^{-1}$ (Barry 1994) and 6.8 ind. ha ${ }^{-1}$ (Wharton 1989) at the current study site, but capture techniques and analysis methods varied, which limits comparability. Only 1 extinct population, from now-filled natural ponds on the eastern slope of the Coast Ranges of San Mateo County, is thought to have supported a similarly high density of T. s. tetrataenia based on the extent of museum collections made in the 1940s (Fox 1951, discussed in
Barry 1994). Reported densities of the eastern garter snake $T$. s. sirtalis, a closely related subspecies, range from 3.7 to 89 ind. ha ${ }^{-1}$ (Fitch 1982, Dalrymple \& Reichenbach 1984). Thus, high densities are not unheard of for the species at large. However, it is notable that we found such a density in an extremely modified, small fragment of recently created habitat.

It is possible that our average estimate of 1762 ind. represents an increase in population abundance from the 300 to 700 ind. estimated at the site in the 1980s (Wharton 1989, Barry 1994); however, the discrepancies in methods preclude direct comparison across these estimates. If an increase in population has occurred between the 1980s and today, it could be due to a high and yet-unattained carrying capacity for $T$. s. tetrataenia on the site (assuming colonization sometime in the 1960s) or to an increase in carrying capacity for $T$. s. tetrataenia at the site over time. It is unlikely that an increase in population size would have been caused by more recent immigration of snakes onto the parcel because the site has been virtually isolated in an urban matrix for the last $40 \mathrm{yr}$. For T. s. tetrataenia at the current study site, the variability in reported abundance and density estimates over time - and the incorporation of this information into management actions for the species - highlights the need for surveys like ours that use standardized methods and robust mark-recapture analyses to replicate effort across years and to generate comparable estimates of abundance.

Irrespective of whether the population size of $T . S$. tetrataenia at our site has increased over the last few decades, it is clear that carrying capacity at this site is high, and we expect that it is related to prey availability, prevalence of refugia, low levels of interspecific competition and sustainable levels of predation at this site. Though not quantified in our study, prevalence of refugia is likely high, as approximately $44 \%$ of our site is upland, covered by heterogeneous scrub, grassland and riparian vegetation, with an apparent high density of rodent burrows. Though not directly studied, interspecific competition for prey resources appears to be low (relative to intraspecific competition) as the only other snake species captured during our surveys tend toward terrestrial prey (Pacific gopher snakes Pituophis catenifer catenifer, Pacific ring-necked snakes Diadophis punctatus amabilis, and western yellow-bellied racers Coluber constrictor mormon). Additionally, daily observations of shorebirds, raptors, fox and weasels - which take aquatic and terrestrial prey - were low across the months we were present at the site. It is notable that no other species of garter snake were captured dur- 
ing our surveys, given the presence of both the Santa Cruz garter snake $T$. atratus atratus and the coast garter snake T. elegans terrestris in other locations of San Mateo County. Predation pressure is apparent, but the degree to which it limits carrying capacity is uncertain. Observed potential predators include feral and domestic cats, raptors, shorebirds, fox, and weasels.

Prey abundance warrants deeper examination as a focus of restoration efforts at the site and as an important factor influencing carrying capacity of snakes (Kephart \& Arnold 1982, Drummond 1983, Madsen \& Shine 2000, McCauley et al. 2006). The marked increase in the number of Pseudacris sierra captures from 2007 to 2013 points to the possibility that habitat restoration activities - specifically expansion and restoration of aquatic habitat over the last $15 \mathrm{yr}$ - have increased the availability of the amphibian prey base on our site. As $P$. sierra are amphibians reliant on water for breeding, it is likely that increases in the area of aquatic habitat and amount of rainfall, which affect hydroperiod, would impact population size of this species. Rainfall records anecdotally rule out the rainfall hypothesis by showing that more rain fell in 2007 when fewer $P$. sierra were captured. However, without a record of $P$. sierra abundance at this site over the years, we have no baseline against which to compare our observations and cannot determine whether the observed fluctuation in captures between 2007 and 2013 are outside of the normal range of variability expected for this population. Thus, the increase in captures could reflect normal, annual fluctuations in population size or a response to habitat enhancement activities (or a combination thereof).

Regardless, between 2007 and 2013, no concurrent increase in the $T . s$. tetrataenia population was observed. If the increase in chorus frog captures reflects a true and sustained increase in availability of prey on the site, the lack of corresponding increase in estimated abundance of $T$. s. tetrataenia may reflect alternative limiting factors for this population, or a delay in population-level response of $T$. s. tetrataenia to the increase in prey abundance/ availability. It is likely that a time lag would occur in the response of predator to prey abundance for this system, given that the energetic benefit of increased prey availability at the individual level may not be observable at the population level until subsequent bouts of reproduction have increased recruitment, precluding observation of effect at this time.

Age demographics are another important measure of population health and viability. T. s. tetrataenia does not display age-class specific phenotypes, so characterization of the population by size distribution assists in delineation of age classes, which provides insight to reproductive potential (Fig. 1). Fitch (1970) found that females of other $T$. sirtalis subspecies reach sexual maturity at approximately 18 mo, equivalent to $<400 \mathrm{~mm}$ SVL based on his age-class designations for the red-sided garter snake T. s. parietalis. We are not aware of a published size cutoff for subadult versus adult snakes in this subspecies, but the smallest gravid female captured in our study points to a minimum size at sexual maturity for females of at least $368 \mathrm{~mm}$. This is in accord with Halstead et al.'s (2011) size distribution of $T$. s. tetrataenia at another site, where a peak in abundance appears at $\sim 300 \mathrm{~mm}$ SVL for females (followed by another peak at larger size), which may reflect a cohort of subadult snakes. In our sample, we found that young-of-year snakes ranged in size from 152 to $\sim 200 \mathrm{~mm}$, which is in agreement with measurements reported for newborns by Barry (1994) and Larsen (1994). It should be noted that our survey periods did not encompass the expected peak of activity for young-of-year T. s. tetrataenia (based on Halstead et al. 2011), and therefore we do not present a reliable maximum size attained for snakes born within the year.

Interestingly, for our study, no snakes were recaptured between 2007 and 2013. This is not unexpected based on our low estimated capture probabilities within the trapping period or on Halstead et al.'s

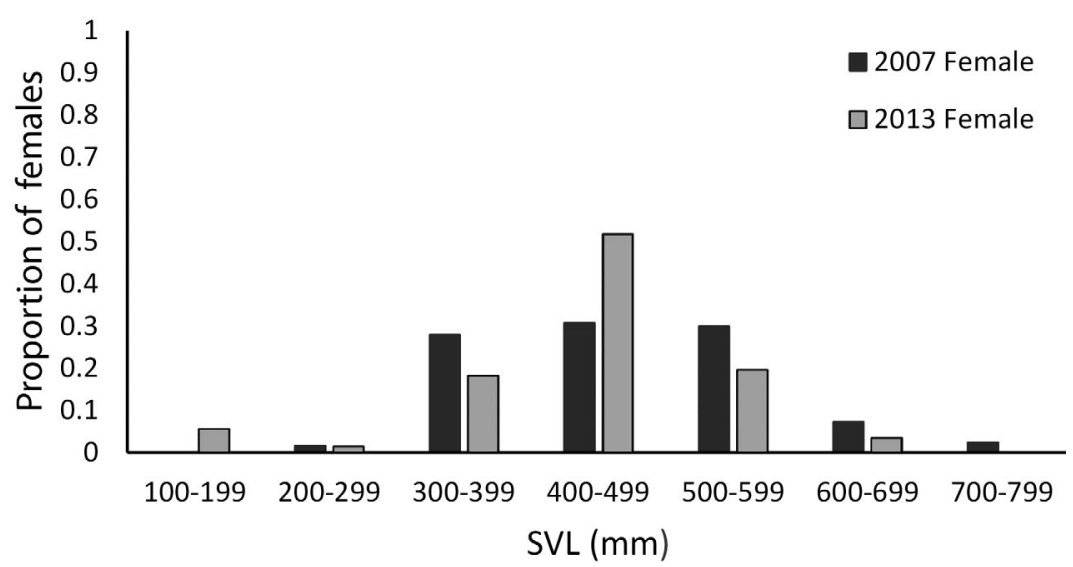

Fig. 1. Size class distribution of female San Francisco garter snakes Thamnophis sirtalis tetrataenia captured at our study site between 29 March and 1 July 2007 , and between 8 April and 14 July 2014. SVL: snout-to-vent length 
(2011) estimated average annual survival for T. $s$. tetrataenia at their site. If applied to our population, Halstead et al.'s (2011) estimate calculates to an average survival of $\sim 0.16$ (i.e. $0.74^{6}$ ) for subadult and adult snakes in the 6 yr interval between our trapping periods. However, the detection of gravid females in both years of our study and the large proportions of mature females available in both years (based on distribution of SVL; Fig. 1), combined with similar point estimates of population size in 2007 and 2013, suggest that our population may be stable and self-sustaining.

Along with population size and age distribution, sex ratio is an important indicator of population robustness (Doak et al. 1994, Le Galliard et al. 2005). Using total numbers of individuals captured in earlier studies at this site, Wharton (1989) reported that females outnumbered males at a ratio of 0.72 , and Larsen (1994) reported males outnumbering females at a ratio of 1.17. Wharton's (1989) study spanned $2.5 \mathrm{yr}$, using trapping and visual surveys, while Larsen's (1994) spanned approximately 20 mo, with variable trapping effort over time. In Halstead et al. (2011), 95\% confidence limits from Bayesian analysis of binomial proportions indicated that their population's sex ratio fell anywhere between 0.85 and1.62. Sex ratios calculated from abundance estimates (obtained by our best supported mark-recapture models) showed that females outnumbered males in both 2007 and 2013 with sex ratios (M:F) of 0.77 and 0.76 , respectively. A sex ratio of 1:1 was considered desirable in the 1985 US Fish \& Wildlife Service recovery plan for T. s. tetrataenia, but a subsequent review suggested that a 1:1 ratio may not be the optimal state for a viable population (USFWS 2006). Studies on other subspecies of $T$. sirtalis found that males outnumbered females in the wild (Shine et al. 2001), but seasonal activity patterns vary by sex and age class and it is clear that the timing, duration, and method of trapping can influence observed sex ratios. For example, Fitch (1965) noted that the observed sex ratio of red-sided garter snakes varied between $0.64,1.13$, and 1.38 depending on the season of data collection (in this case: summer, spring plus fall, and fall only). Wharton (1989) also reported variable sex ratio for $T$. s. tetrataenia at our site, dependent upon month used to summarize data. Thus, additional studies are needed to assess time-varying sex ratio at our site and to determine an appropriate target ratio for T. s. tetrataenia conservation.

Recovery of T. s. tetrataenia relies on the establishment and maintenance of multiple, robust, and viable populations (USFWS 1985, 2006). Specifically, the recovery plan calls for 10 such populations before the subspecies can be considered for downlisting (USFWS 1985). Currently, only 2 populations (from our study site and from Halstead et al. 2011) have well-documented demographic data; both populations appear to be stable or increasing, though additional surveys are needed to determine long-term trends at both sites. Other known populations on the peninsula have not been subjected to standardized demographic studies, and thus progress toward recovery goals is unclear. Further study is needed to determine the size, age-class distribution, sex ratio, and trend of all T. s. tetrataenia populations to understand whether current recovery goals have been met and whether they are in accord with the biology of the species.

Our study suggests that $T$. s. tetrataenia are capable of thriving in relatively small, disturbed areas provided that suitable habitat is present. Thus, T. $s$. tetrataenia populations in similar areas within the current range have the potential to respond to conservation efforts. Unlike large-bodied species with extensive home ranges requiring vast natural reserves, our results suggest that $T$. s. tetrataenia recovery may be achieved with a model of small, interconnected areas of protected habitat in addition to existing larger natural tracts. Even small areas of new habitat might greatly contribute to the overall subspecies population.

Our findings highlight the potential for increased use of reserve designs that are more compatible with urban development. Interconnected parks in urban areas, if managed for native species, could contribute greatly to the conservation and recovery of sensitive species with small home ranges. The debate between single large and several small (SLOSS) reserves has been covered extensively in the literature; several studies suggest there may be no general rule and that individual species and goals should direct reserve design (Simberloff \& Abele 1982, Soule 1986, McCoy \& Mushinsky 1999). In the case of T. s. tetrataenia, it appears the subspecies can thrive not only in large tracts of natural habitat but also in a small plot surrounded by a highly urbanized environmen - supporting the idea that conservation of endangered species may be successful even in the absence of ideal conditions.

Acknowledgements. We thank the employees of the City of San Francisco for their support during this study. Numerous field assistants were instrumental to the implementation of this study, including T. Lim, C. Swaim, J. Mitchell, W. Bauer, C. Paris, E. Britt, S. McLintock, A. Scott, A. Murphy, B. 
Roumasset, B. Hanshew, C. Klinkowski, E. Bjerre, J. Kunna, M. Yacelga, S. Santos, S. Kim, and T. Canitia. We thank B. Halstead, E. Bjerre, and anonymous reviewers for comments on the study design and/or manuscript. We also acknowledge J. Warton, S. Larsen, and S. Barry whose syntheses of information in the form of unpublished Master's theses provided a solid foundation for our subsequent effort at the study site. The study was funded by SFO and Swaim Biological, Inc. Snakes were handled as stipulated in US Fish \& Wildlife Service Recovery Permits TE-815537-1 and TE176209-2 and California Fish \& Wildlife Memorandum of Understanding (SCP-002672).

\section{LITERATURE CITED}

Anderson DR (2008) Model based inference in the life sciences: a primer on evidence. Springer, New York, NY

Barry SJ (1978) Status of the San Francisco garter snake. Inland Fisheries Endangered Species Program Special Publication 78-2, California Department of Fish and Game, Sacramento, CA

Barry SJ (1994) The distribution, habitat and evolution of the San Francisco garter snake, Thamnophis sirtalis tetrataenia. MSc thesis, University of California, Davis, CA

Blainville HMD (1835) Description de quelques espèces de reptiles de la Californie précédée de l'analyse d'un système general d'erpétologie et d'amphibiologie. Nouv Ann Mus Hist Nat Paris 4:233-296

Burnham KP, Anderson DR (2002) Model selection and multimodel inference: a practical information-theoretic approach. Springer-Verlag, New York, NY

Burnham KP, Anderson DR (2004) Multimodel inference: understanding AIC and BIC in model selection. Sociol Methods Res 33:261-304

Dalrymple GH, Reichenbach NG (1984) Management of an endangered species of snake in Ohio, USA. Biol Conserv 30:195-200

Debinski DM, Holt RD (2000) A survey and overview of habitat fragmentation experiments. Conserv Biol 14: 342-355

> Doak D, Kareiva P, Kleptka B (1994) Modeling population viability for the desert tortoise in the Western Mojave Desert. Ecol Appl 4:446-460

Drummond H (1983) Aquatic foraging in garter snakes: a comparison of specialists and generalists. Behaviour 86: $1-30$

ESA (1973) US Endangered Species Act of 1973, as amended through the 108th Congress. Public Law No. 93-205, 87 Stat. 884 (Dec. 28, 1973), US Fish \& Wildlife Service, Washington, DC. www.fws.gov/endangered/esa-library/ pdf/ESAall.pdf

Fitch HS (1965) An ecological study of the garter snake, Thamnophis sirtalis. Univ Kans Mus Nat Hist 15:493-564

Fitch HS (1970) Reproductive cycles in lizards and snakes. Univ Kans Mus Nat Hist 52:1-247

Fitch HS (1982) Resources of a snake community in prairiewoodland habitat of northeastern Kansas. In: Scott NJ (ed) Herpetological communities. US Fish Wildl Serv Wildl Res Rep 13, Washington, DC, p 83-97

Fox W (1951) The status of the gartersnake, Thamnophis sirtalis tetrataenia. Copeia 1951:257-267

Halstead BJ, Wylie GD, Amarello M, Smith JJ, Thompson ME, Routman EJ, Casazza ML (2011) Demography of the San Francisco gartersnake in coastal San Mateo County,
California. J Fish Wildl Manage 2:41-48

Harding JH (1997) Amphibians and reptiles of the Great Lakes region (Great Lakes environment). University of Michigan Press, Ann Arbor, MI

Huggins RM (1989) On the statistical analysis of capturerecapture experiments. Biometrika 76:133-140

> Huggins RM (1991) Some practical aspects of a conditional likelihood approach to capture experiments. Biometrics 47:725-732

Kephart DG, Arnold SJ (1982) Garter snake diets in a fluctuating environment: a seven-year study. Ecology 63: 1232-1236

> Krauss J, Bommarco R, Guardiola M, Heikkinen RK and others (2010) Habitat fragmentation causes immediate and time-delayed biodiversity loss at different trophic levels. Ecol Lett 13:597-605

Laake JL (2013) RMark: an R interface for analysis of capture-recapture data with MARK. AFSC Processed Rep 2013-01, Alaska Fish Sci Cent, NOAA, Natl Mar Fish Serv, Seattle, WA

Larsen SS (1994) Life history aspects of the San Francisco garter snake at the Millbrae habitat site. MSc thesis, California State University, Hayward, CA

Larsen SS, Swaim KE, McGinnis SM (1991) Innate response of the San Francisco garter snake and Alameda whipsnake to specific prey items. Trans West Sec Wildl Soc 27: 37-41. https://www.wildlifeprofessional.org/western/ transactions/transactions_1991_5.pdf

> Le Galliard JF, Fitze PS, Ferriere R, Colbert J (2005) Sex ratio bias, male aggression, and population collapse in lizards. Proc Natl Acad Sci USA 102:18231-18236

> Madsen T, Shine R (2000) Rain, fish and snakes: climatically driven population dynamics of Arafura filesnakes in tropical Australia. Oecologia 124:208-215

> McCauley DJ, Keesing F, Young TP, Allan BF, Pringle RM (2006) Indirect effects of large herbivores on snakes in an African savanna. Ecology 87:2657-2663

> McCoy ED, Mushinsky HR (1999) Habitat fragmentation and the abundances of vertebrates in the Florida scrub. Ecology 80:2526-2538

McGinnis SM (1984) The current distribution and habitat requirements of the San Francisco garter snake (Thamnophis sirtalis tetrataenia) in Coastal San Mateo County. Final Report of Work Conducted Under Interagency Agreement C-673, California Department of Fish \& Game, Sacramento, CA

> Mora C, Sale PF (2011) Ongoing global biodiversity loss and the need to move beyond protected areas: a review of the technical and practical shortcomings of protected areas on land and sea. Mar Ecol Prog Ser 434:251-266

Sala OE, Chapin FS III, Armesto JJ, Berlow E and others (2000) Global biodiversity scenarios for the year 2100 . Science 287:1770-1774

Shine R, LeMaster MP, Moore IT, Olsson MM, Mason RT (2001) Bumpus in the snake den: effects of sex, size and body condition on mortality of red-sided garter snakes. Evolution 55:598-604

Simberloff D, Abele LG (1982) Refuge design and island biogeographic theory: effects of fragmentation. Am Nat 120: $41-50$

> Soule ME (1986) What do genetics and ecology tell us about the design of reserves? Biol Conserv 35:19-40

Stebbins RC, McGinnis SM (2012) Field guide to amphibians and reptiles of California. University of California Press, Berkeley, CA 
USFWS (1967) Native fish and wildlife: endangered species. US Fish \& Wildlife Service, Washington, DC. Fed Regist 32:4001

USFWS (1985) Recovery plan for the San Francisco garter snake Thamnophis sirtalis tetrataenia. US Fish \& Wildlife Service, Portland, OR

USFWS (2006) San Francisco garter snake (Thamnophis sirtalis tetrataenia) 5-year review: summary and evaluation. US Fish \& Wildlife Service, Sacramento, CA

Vitousek PM (1994) Beyond global warming: ecology and global change. Ecology 75:1861-1876

Wharton JC (1989) Ecological and life history aspects of the San Francisco garter snake (Thamnophis sirtalis tetratae-

Editorial responsibility: Luca Luiselli,

Rome, Italy nia). MSc thesis, San Francisco State University, San Francisco, CA

White GC, Burnham KP (1999) Program MARK: survival estimation from populations of marked animals. Bird Study 46:S120-S139

Wilcove DS, Rothstein D, Dubow J, Phillips A, Losos E (1998) Quantifying threats to imperiled species in the United States: assessing the relative importance of habitat destruction, alien species, pollution, overexploitation, and disease. Bioscience 48:607-615

Williams BK, Nichols JD, Conroy MJ (2002) Analysis and management of animal populations. Academic Press, San Diego, CA

Submitted: September 9, 2014; Accepted: April 6, 2015 Proofs received from author(s): June 18, 2015 